\title{
Evolution of the concept of a balanced indicator system
}

\author{
Olga Trofimova*, Gulnaz Kalimullina \\ Ural Institute of Management - branch of RANEPA, Ekaterinburg, Russia
}

\begin{abstract}
The aim of this research is to analyze the evolution of the balanced scorecard concept. To do this, the article describes the evolution of the concept of a balanced scorecard in a historical context. Namely, 3 stages of the formation of this system are considered. For each stage, comments are given by the author with a description of the identified problems. The analysis outlines an approach to education and the development of a new balanced scorecard. The described system of indicators makes it possible to link multilateral indicators for balanced development in different economic entities. The authors come to the conclusion that the competent and comprehensive use of the balanced scorecard tools leads not only to an overall reduction in financial costs, but also allows to increase the quality of the services provided in general.
\end{abstract}

\section{Introduction}

The relevance of the chosen topic is due to the strengthening of criticism of traditional management and the need to search for improved models for organizing control. From 1992 to the present time, interest in the balanced scorecard has been steadily growing. More and more Russian companies are introducing the entire balanced scorecard or its elements.

Developed in the 1990s by Robert Kaplan, a professor of Business school at Harvard University, and David Norton, a management consultant [1], this system was designed to solve the problem of improving company performance and standardizing the reporting system. At the same time, the considered methodology is suitable for solving the problem of unstructured information flow, which can often be belated and contradictory. Of great value to management is the model of non-financial performance indicators of the organization used in this methodology, which makes it possible to track the achievement of goals as part of the implementation of the company's strategy.

In the evolution of the balanced scorecard, several main stages of development can be distinguished (Figure 1):

* Corresponding author: trofimova-om@,ranepa.ru 

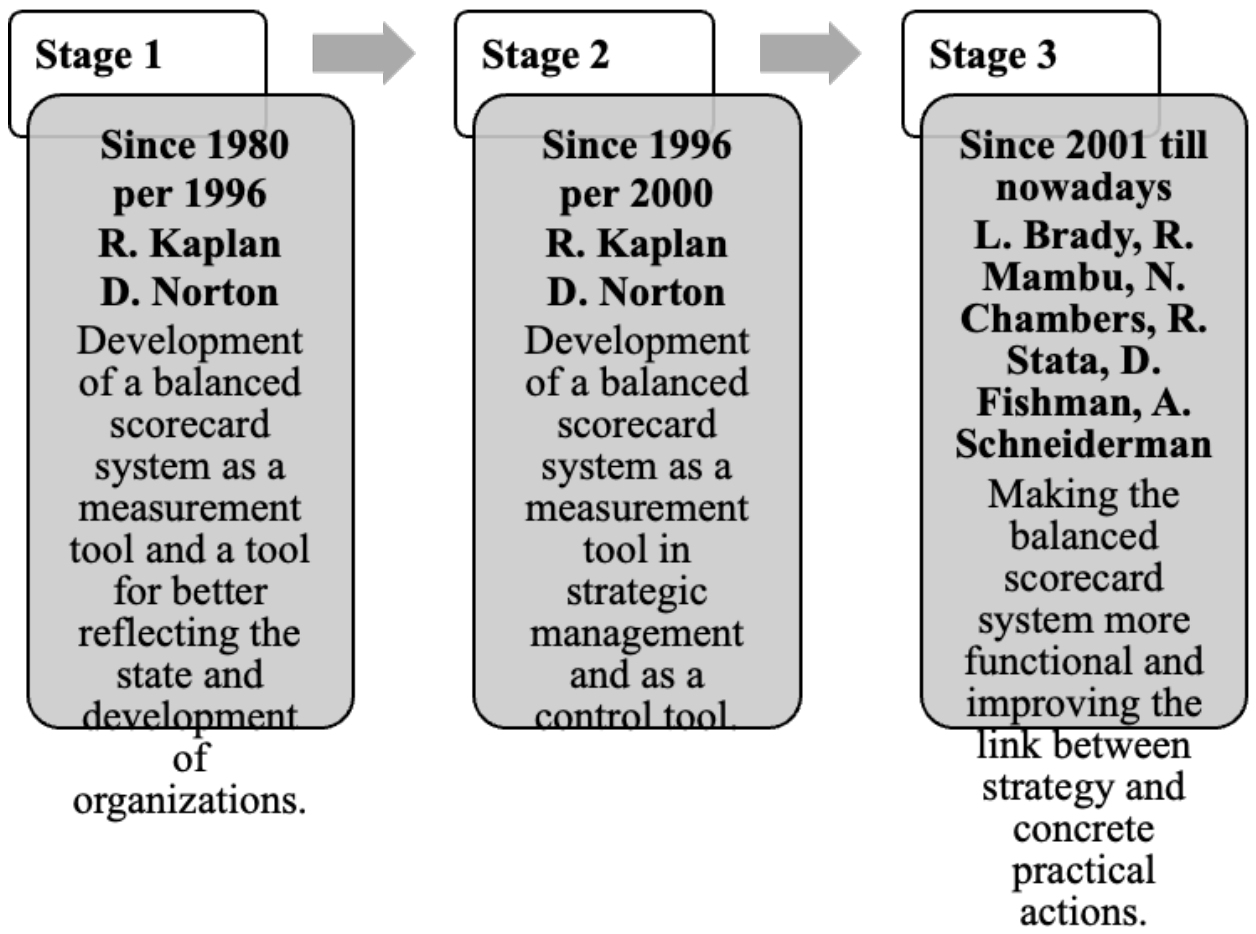

Fig. 1. Stages of development of the balanced scorecard.

For the first time people heard about the balanced scorecard in the late 1980s and early 1990s. The balanced scorecard was a tool for strategic management within individual companies.

During these years, economics professors Kaplan and Norton studied American large and small companies in detail in order to create a unique system for assessing the state of the organization and found that almost all companies pay attention only to financial business management tools. At the same time, in order to improve short-term financial indicators, the costs of training and financial incentives for employees were reduced. Marketing and advertising expenses were also reduced. And the worst thing is, the costs were reduced for customer service, which then decreased. Customers are one of the main indicators of the company. Ignoring them means losing profits.

\section{Material and Methods}

Kaplan and Norton came to the quite obvious conclusion that the basis of the methodology for evaluating the effectiveness of an enterprise solely by financial indicators deprives the growth of the future economic value of the organization.

Economists in the course of their research have recorded that the company's personnel do not understand their role in the implementation of the strategy and are not sufficiently motivated to improve the effectiveness of the implementation of long-term plans. Out of $100 \%$, only $25 \%$ of senior staff receive bonuses directly related to the implementation of the strategy. And there is an example when $55 \%$ of organizations do not link their budget to the implementation of the strategy at all.

To eliminate the identified problems, Norton and Kaplan developed the concept of a balanced scorecard. Researchers widely applied the developed model in a number of American companies, and in the late 1990s Norton and Kaplan described their thoughts in a 
scientific publication. They described the theory and actual approaches to management. The world saw the article "Indicators Leading to Efficiency" in Harvard Business Review.

After the publication of this article, my companies put into practice the knowledge gained. This has yielded great results. A balanced scorecard was found useful not only for measuring results, but also for strategic management.

After the successful publication of the scientific article, the professors continued to develop the concept of a balanced scorecard and published 3 useful books. The first book was published in 1996. This book is called "Balanced Scorecard. From strategy to action". The second book was published in 2000. The book is called "Strategy-oriented Organization", and the third book is "Strategic Maps". All these books are still very popular in many countries.

\section{Result and Discussion}

This is not the end of the development of the balanced scorecard system. After a short time, the Balanced Scorecard Collaborative consulting company, headed by R. Kaplan and D. Norton, developed functional standards - minimum requirements that software supporting a balanced scorecard must meet. The structure of the system should include six main elements: prospects, strategic goals, indicators, objective values, causal relationships, strategic initiatives.

The development of the balanced scorecard as a measuring tool marks various stages of its improvement, which are primarily associated with the enrichment of the parameters included in it and the study of links and interrelationships between them. On the basis of a gradual understanding of the new factors of success of organizations, the range of indicators included in the balanced scorecard is being expanded and refined, approaches and methods for measuring their values are being developed and implemented. Central to this process is to increase the focus and ability of organizations to explore the relationships between different indicators and rank them according to their role in strategy. As a result, at the beginning of the century, significant leadership in the implementation of the balanced scorecard reached the necessary maturity of capabilities for operationalizing the strategy in indicator models.

Achievements in the development and implementation of the balanced scorecard at the organizational and executive level and as a tool for strategic control lead to the spread of this process in the structural divisions of the organization. Leading implementation organizations are striving to form a hierarchically structured balanced scorecard, including an individual level.

Thus, the balanced scorecard has fully established itself as a monitoring and evaluation tool and a central factor in targeted efforts at all organizational levels to implement the strategy. The development of a balanced scorecard in all areas was stimulated and accelerated by the development and dissemination of computer management technologies that facilitate the use of a balanced scorecard.

The development of technologies is one of the key values in the development of a system of balanced indicators. New technologies allow analyzing "old" indicators in a new way. The development of Excel programs was very important. Currently, Excel allows you to build dashboards, which in turn perfectly help in research.

The evolution of the balanced scorecard of the third generation is a methodology for managing and evaluating the activities of organizations on the way to achieving strategic goals. The third generation of the model solves such typical problems as lack of responsibility for management, monitoring only financial criteria and the inability to force the management system to develop and improve. 
Ideas of the third generation balanced scorecard are based on the following key postulates of business management and strategic management (Figure 2).

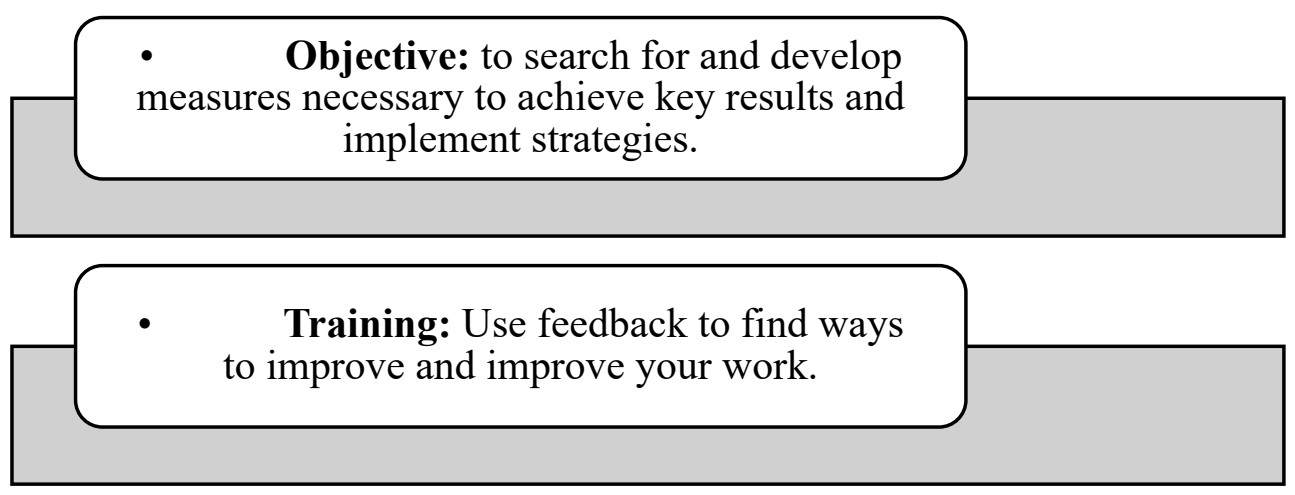

- Responsibility: Use consensus so that everyone understands what needs to be done and fully participates in this process.

\section{- Communication: providing clear and unambiguous information to disclose the purpose and optimize organizational activities.}

Fig. 2. The main postulates of the third generation balanced scorecard.

A significant breakthrough in the evolution of the balanced scorecard is the realization that the successful use of this tool depends not only on the use of the correct methods for selecting the criteria included in it, but also on the fact that organizations are implementing the correct management processes that allow managers to use it effectively. These provisions substantiate the development of a balanced scorecard as a management and control system with characteristic features:

- Pronounced formulation of "desirable state" or strategic purpose (positioning);

- Medium-term strategic objectives to be assessed, broken down into activities and outcomes and, if necessary, standardized perspectives;

- Specific and well-defined goals, interpreted based on vision, mission and strategy;

- Priority initiatives related to the structuring and implementation of strategic goals;

- Analysis of the expectations and needs of the organization and, on this basis, the formation of criteria for determining the key characteristics, defined as a system of criteria.

Each balanced scorecard must contain six mandatory elements that form the core of the system (Figure 3): 


\section{Perspectives}

\section{Strategic initiatives}

\section{Measures}

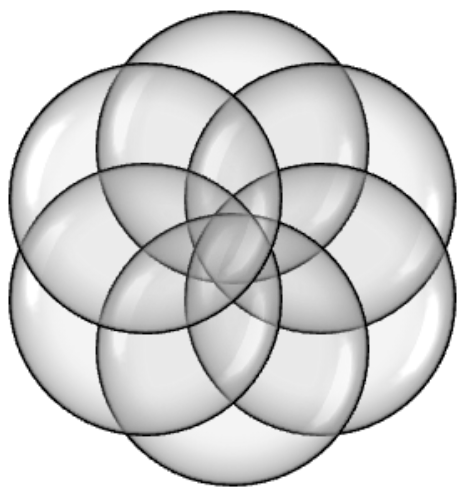

\section{Objectives}

\section{Targets}

\section{Cause and effect linkages}

Fig. 3. Mandatory elements of the balanced scorecard.

Perspectives - elements for strategy decomposition.

Objectives - determine the direction of the strategy implementation.

Measures - metrics that reflect progress towards achieving a strategic goal, indicate how the strategy should be implemented at the operational level.

Targets are quantitative expressions of the level that a particular indicator must reach.

Cause and effect linkages link a company's goals into a single chain.

Strategic initiatives - projects that contribute to the achievement of goals.

Without these elements, it is very difficult to imagine a modern balanced scorecard model.

It is also worth highlighting the stages of creating a balanced scorecard (Figure 4.)
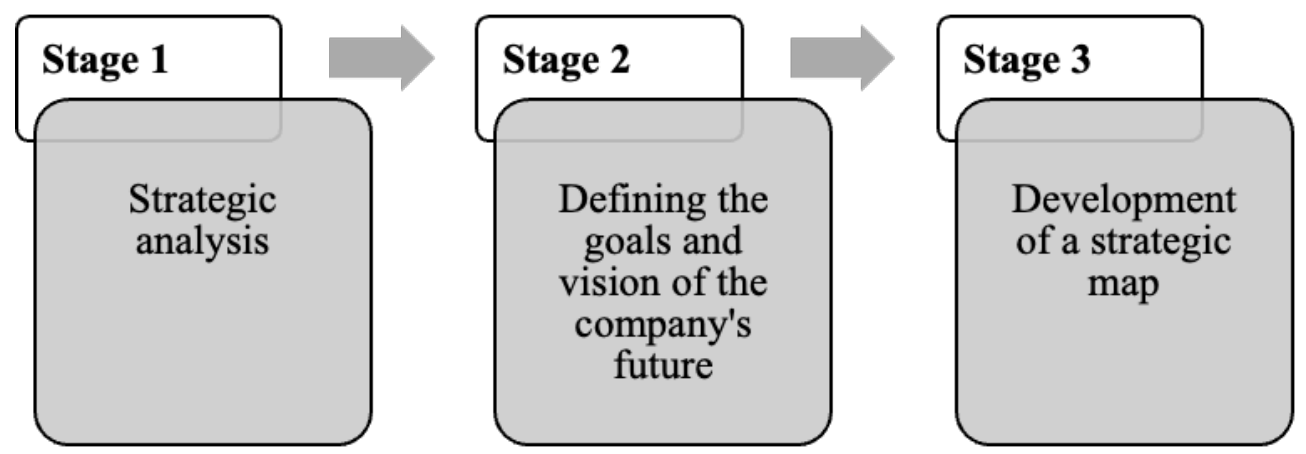

Fig. 4. Stages of creating a balanced scorecard.

At the first stage, a strategic analysis of the company is carried out, for example, using PEST, SWOT, SNW. These tools are good at collecting data about the external and internal environment of the company, its strengths and weaknesses, assessing risks and prospects. Using these types of analysis, you can look at several external factors, for example, politics, 
technology, society and the economy. Internal factors are also analyzed. This all gives an idea of the big picture, inside the company and outside.

At the 2nd stage, the vision of the company is formed, i.e. a mission, vision, strategic goals and core values are formed. The next step is to define strategic objectives and initiatives. Tasks are problems, in the solution of which the goal will be achieved. Initiatives are projects that need to be created in order for a goal to be realized.

In this way, the core of the balanced scorecard is formed, the visual display of which will be the strategic map of the organization.

At the 3rd stage, a strategic map is developed. To create a map, determine the cause and effect linkages between strategic objectives. Thus, the goals of the company become interconnected by a logical chain, which is built on the principle of "if - then". The set of goals and connections between them forms the strategic map of the organization. An example of a simple strategic company map is shown in Table 1.

Table 1. Example of a company strategic map.

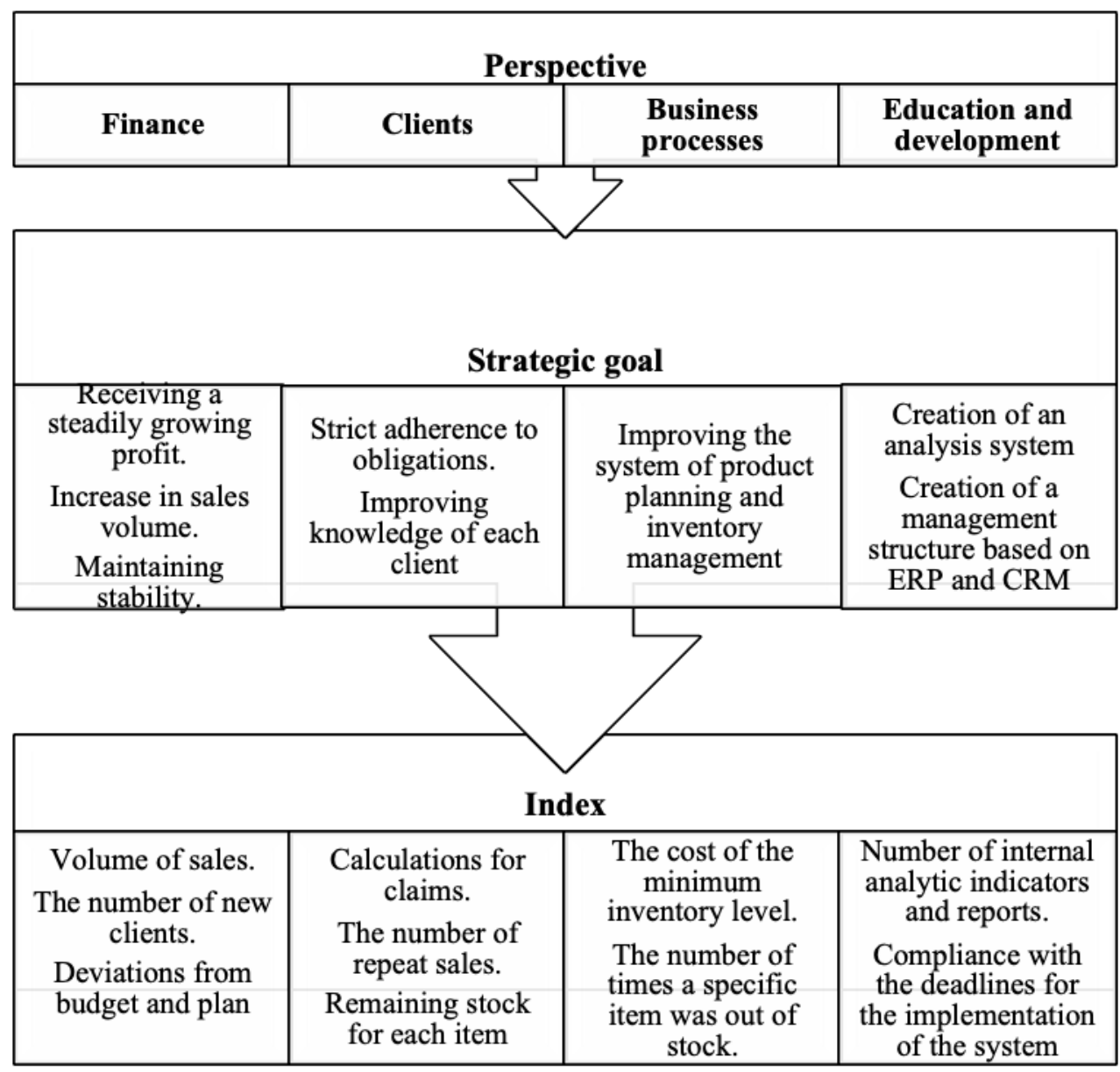

At the present stage of the evolution of the balanced scorecard, the results of the work are assessed by comparing the plan and the fact with clarification of the reasons for the deviations. As a result, either the target value of the indicators or the strategic measures are adjusted. 
There are a number of examples of successful implementation of a balanced scorecard in the business world. Gradually being introduced into the work of various companies, the balanced scorecard system accumulates useful experience. Companies that have applied this system in their activities show very high results.

One of the examples of successful implementation of the balanced scorecard system is the American corporations "Mobil U.S. Marketing and Processing" and "Cigna Property and Casualty".

The example of the first company shows well how to turn from a loss-making company into a highly profitable company with a good income. The second company showed no less good results. The insurance company showed annual revenue of more than $\$ 3$ billion. These examples inspire many other companies to apply a system of balanced indicators in their activities.

\section{Conclusion}

An analysis of the evolution of the concept of a balanced scorecard identifies clear trends in development and improvement alternatives. This gives us the opportunity to draw the following conclusions [13]:

Firstly, a balanced scorecard is turning from a tool for increasing the value of organizational efficiency into a tool for managing and controlling strategy. Thus, it can be assumed that a peculiar expression of the transition in managerial thinking is formed in terms of management control systems in which the financial burden is redirected towards strategic management. Financial indicators are not the only indicators that need to be evaluated.

Secondly, the development of the idea of a learning organization finds a particularly strong charge in the coordination of strategic management concepts and a balanced scorecard. Although the models of strategic adjustment were noted and adjusted using feedback on the behavior of the organization in question, this process recorded a deepening into a balanced scorecard. This is the most convenient form of obtaining information from the staff. So we can adjust our actions by discussing them with everyone.

In this case, we can even talk about deep forms of organizational self-improvement and learning. This developing trend provides certain incentives to create value in the organization. It is very important to arrange meetings where we can hear the opinion of each employee. In the future, such meetings will allow you to build successful relationships with customers, open doors for innovation and develop the company to a high level. All this is possible when we shift the emphasis from financial indicators to intangible ones, that is, to an economy based on intangible assets, knowledge and services. It is necessary to pay special attention to this. Saving on intangible assets leads to business stagnation, and sometimes to degradation. At the same time, it should be taken into account that all indicators should be evaluated in a balanced manner. Forget about the economy is not worth it.

Thirdly, as the most important moment in the process of analyzing the relationship between the concepts of strategic management and control and a balanced system of indicators is their coordination and the formation of a qualitatively new model [8].

These three conclusions indicate that, in concrete examples, a balanced scorecard is used as an excellent tool for strategic management and control.

At the last stage of the evolution of the concept, there is a revolution in the indicators of evaluating not only the effectiveness of organizational activity, but, above all, its strategy. Along with the imposition of strategic maps as a tool for effective management and precise control, the latest developments in the field of maps are presented as a brilliant, accurate 
and holistic method of consolidating the most important moments in the art of modern management and tasks of modern control.

Thus, a balanced scorecard is a timely idea. Outdated traditional measurement systems, as well as ever-increasing efforts to overcome increasingly complex conditions, provide great opportunities for a balanced scorecard.

A balanced scorecard looks simple, but it has a great variety in its nature. The advantage is that, at first glance, there is sufficient transparency and clarity. However, with a deeper study of the concept itself, it becomes clear that the so-called "simplicity" is only apparent. Competent and comprehensive use of the tools of a balanced scorecard leads not only to an overall reduction in financial costs, but also allows you to improve the quality of services provided in general.

\section{References}

1. R. Kaplan, D. Norton, Balanced Scorecard, From strategy to action (M.: CJSC "Olymp-Business", 2008)

2. N.-G. Olwe, K.-J. Petri, J. Roy, S. Roy, Balance between strategy and control. Make the MSC scorecard work (SPb: Peter, 2014)

3. D. I. Rytsev, Problems of the Balansed Storecard (KPI) as a tool for developing and implementing a strategy in the system of strategic enterprise management (2019). Access mode: http://perfect-industries.ru/strategy/balanced-scorecard.html\#.U7pxKBe $\mathrm{R}$

4. A. M. Zhemchugov, M. K. Zhemchugov, Russian Entrepreneurship, 2, 86-91 (2010)

5. J. B. Quinn, Strategy of Change, Strategic process (SPb.: Peter, 2018)

6. A. M. Zhemchugov, M. K. Zhemchugov, Problems of Economics and Management, 11, 3-12 (2012)

7. K. Hubert, Rumpersade. Individual balanced scorecard. The path to personal happiness, harmonious development and growth of the organization (M.: CJSC "Olymp-Business", 2015)

8. P. F. Drucker, Management practice (M.: Williams, 2007)

9. A. M. Schneiderman, Journal of Strategic Performance Measurement, 7 (1999)

10. H. Norreklit, The balance on the balanced in the scorecard - a critical analysis of some of its assumptions (Management Accounting Research, 2000)

11. A. Gautreau, B. Kleiner, Management Research News, 24, 153-156 (2001)

12. W. E. Deming, Out of the Crisis: A New Paradigm for Managing People, Systems and Processes (M.: Alpina Business Books, 2007)

13. P. F. Drucker, Effective manager (M.: Book Chamber International, 2004)

14. V. G. Belinsky, Complete works in 13 volumes (M.: Publishing house of the Academy of Sciences of the USSR, 1953 - 1959)

15. B. Maskell, Making the Numbers Count, Second Edition: The Accountant as Change Agent on the World-Class Team (Productivity Press, 2 edition, 2009)

16. D. Bakatina, Zh-P. Duviesar, V. Klintsov, V. G. Belinsky, Effective Russia. Productivity as a foundation for growth (McKinsey Global Institute, 2016) 